\title{
Vamos fazer da nossa vida uma obra de arte?
}

\section{Let us make our lives a work of art?}

\author{
Ana Maria de Campos $^{1}$ \\ Graziela Giusti Pachane ${ }^{2}$
}

\begin{abstract}
RESUMO
Apresentamos neste artigo uma pesquisa educacional como caminho investigativo trilhado na companhia de muitas pessoas. Recorremos às narrativas de algumas educadoras populares para compartilhar uma experiência de formação realizada na cidade de Campinas-SP, no período compreendido entre 2003-2004. Procuramos abordar a formação e o trabalho realizado nos grupos de alfabetização de jovens e adultos, como vivência significativa na vida de todos os participantes do processo. A relevância da experiência pode ser apreendida através das narrativas, impregnadas da compreensão que as educadoras têm de si e do trabalho que desenvolvem em parceria com formadores e educandos, todos sujeitos produtores de uma outra e nova interpretação do vivido. A atitude autoral presente nas narrativas e nas opções de vida evidenciam que a concepção emancipatória da produção do conhecimento experimentada na Educação Popular favorece o desenvolvimento da inteligência e das energias criativas das pessoas. A re-significação da vida como uma obra de arte, inconclusa e aberta, pode ser vislumbrada através dos registros dos sujeitos: educadoras e pesquisadores.

Palavras-chave: produção do conhecimento; formação de educadores; educação popular.
\end{abstract}

\begin{abstract}
This article presents an educational research as an investigative way developed together with many people. We have counted on the narrative of some female popular educators in order to share a professional deve-
\end{abstract}

1 Doutoranda em Educação pelo Grupo de Estudos e Pesquisas em Educação Continuada (GEPEC) - Faculdade de Educação da Universidade Estadual de Campinas (UNICAMP). Mestre em Educação pela Pontifícia Universidade Católica de Campinas, Brasil. E-mail: belobelo_22@ yahoo.com.br.

2 Professora Adjunta do Ciclo Comum das Licenciaturas da Universidade Federal do Triângulo Mineiro (UFTM), Brasil. 
lopment experience carried out in the city of Campinas-SP, in the period between 2003-2004. We tried to show how the teachers' education and the work developed by them in a literacy program for youngsters and adults had an impact in the life of all the people involved in the process. The importance of the experience can be seen through the narratives, which are full of the understanding of those educators about themselves and the work developed along with professors and students, all of them producers of a new and different comprehension of the lived experience. The educators' attitude manifested in their narratives, as writers, and in their life choices indicates that the emancipatory conception of knowledge production, as experienced in Popular Education allows the development of people's intelligence and creative energy. The new meaning of life as a work of art, unfinished and open, can be seen by the writings of the subjects involved in this program: educators and researchers.

Keywords: knowledge production; educators development; popular education.

\title{
Introdução
}

\author{
A toda hora rola uma história \\ Que é preciso estar atento \\ A todo instante rola um movimento \\ Que muda o rumo dos ventos \\ Paulinho da Viola
}

Nossa história de vida é feita de muitas pequenas histórias. Histórias que não cessam de acontecer, retomar, recomeçar ou principiar. "A toda hora rola uma história" cantou o poetamúsico Paulinho da Viola.

Uma pesquisa acadêmica também pode ser vivida como uma das inúmeras histórias das nossas vidas. Connelly e Clandinin (CONNELLY; CLANDININ, 1995, p. 11) escreveram que nós somos seres que vivemos vidas relatadas. Narramos as experiências para atribuirmos a elas alguns dos sentidos que percebemos e que talvez olhares distintos não vejam. Outros olhos podem atribuir novos sentidos insuspeitos para nós mesmos. Esta riqueza e diversidade de olhares e interpretações compõem um cenário importante no campo da produção do conhecimento porque ampliam as possibilidades de não desperdiçarmos a experiência, apelo sensato feito pelo sociólogo Boaventura de Sousa Santos (2004 e 2005). 
A vivência de uma pesquisa acadêmica, em algumas situações, pode ser comparada a um vulcão. Aparentemente adormecido durante um tempo, de um momento para o outro retoma suas atividades, despejando lavas incandescentes nos arredores. No campo da educação, tentar compreender as questões que nos inquietam, muitas vezes, nos põe em "erupção". Especialmente se buscamos nas nossas próprias memórias as interrogações que nos empurraram para 0 caminho da pesquisa. $\mathrm{O}$ vulcão adormecido pode começar a cuspir suas lavas a qualquer momento...

Narrar o que encontramos no nosso "Baú de achados e guardados" pode vir a ser mais que um burocrático relatório para entidades financiadoras de pesquisas e transformar-se em um registro no qual, ao tecermos as nossas histórias, também alimentamos sonhos. Sonhos, entre outros, de superação das nossas incompreensões e erros, pois somos educadores, ou seja, gente. Gente que acerta e que erra. Daí podemos compreender também que educadores são seres essencialmente contadores de histórias. Tecendo nossas histórias, fortalecemos o sentido de pertencimento a um grupo social que pode fazer do seu trabalho uma oportunidade de transformação da sociedade. Transformação que se vive e que se vê na vida cotidiana das pessoas comuns. Das crianças, jovens e adultos com os quais trabalhamos e também das nossas próprias vidas, pois aprendemos constantemente com educandos, com outros educadores, com a vida, enfim, com a reflexão sobre a nossa própria prática. Docentes aprendentes, segundo Paulo Freire (FREIRE, 2003, p. 23). Narrando nossos achados de pesquisa contamos novamente, agora para um círculo maior de pessoas o que encontramos no percurso, com a intenção de criar oportunidades de novas aproximações dos velhos problemas. E como é importante deixarmos visíveis as pistas do percurso para que outros possam segui-lo, ou se inspirar nele. Algo que comumente é ocultado na divulgação de resultados das pesquisas, como se toda tese, todo artigo, saísse de nossas mãos, num único movimento, pronto e acabado!

Tratamos neste trabalho da formação de educadores envolvidos com a alfabetização de jovens e adultos. Problema antigo e sempre atualizado numa sociedade desigual que exclui dos direitos sociais aqueles a quem considera “descartáveis" para a manutenção do seu "metabolismo social” (MÈSZÁROS, 2005). Apresentamos a pesquisa como um caminho investigativo trilhado na companhia de muitas pessoas e, ao mesmo tempo, "hospedamos" carinhosamente em nosso texto as narrativas de algumas Educadoras Populares a fim de amplificar as suas vozes de tal maneira que sejam audíveis nos espaços acadêmicos. 


\section{A pesquisa: a que(m) será que se destina?}

Existirmos a que será que se destina?

Caetano Veloso

Essa pesquisa teve como motivação inicial interrogações sobre as transformações que estavam acontecendo na vida de diversas educadoras que participavam de um projeto de alfabetização de jovens e adultos, na cidade de Campinas, SP. O Projeto chamava-se LETRAVIVA, versão local do Programa Brasil Alfabetizado, do MEC. Nosso interesse começou quando algumas educadoras nos relataram que aquela experiência estava transformando totalmente suas vidas. Era o ano de $2003 \mathrm{e} \mathrm{eu}$, juntamente com outra educadora, trabalhava como Coordenadora do Projeto LETRAVIVA, sendo responsável pela formação dos educadores, dentre outras atribuições administrativas.

Por que elas afirmavam, tão categoricamente, as mudanças que estavam se operando em suas vidas? Na narrativa que uma das educadoras nos entregou, em 2004, algumas pistas se insinuavam:

Letraviva... Esperança de vida

No ano de 2003 a vida me pregou uma grande peça... eu diria mesmo uma tremenda rasteira. Em 7 de março meu pai faleceu. Quando recebemos a notícia, minha mãe passou mal, levei-a imediatamente ao pronto-socorro, mas ela não resistiu... Assim, velei meu pai e minha mãe no mesmo dia e os enterrei no mesmo instante,

Como duas flores unidas;

Como duas rosas nascidas

Talvez no mesmo arrebol;

Vivendo no mesmo galho

Da mesma gota de orvalho;

Do mesmo raio de sol... 
Entrei num profundo desespero. Faltou-me chão. O vazio que ficou em mim era imenso. Eu não tinha mais referencial... perdi minha identidade... Uma semana depois, em meio a toda essa dor, acompanhei minha filha a Ouro Preto, pois, ela havia entrado na UFOP e ia estudar por 4 anos. Uma amiga nos acompanhou. Quando ela me perguntou se eu estava triste, lhe respondi que nada podia ser comparado ao que tinha vivido há uma semana atrás. Voltei para minha outra filha em Campinas e deixei A. muito fragilizada em Ouro Preto. Tentava ser forte por elas. Lamento dizer, que não consegui. A ausência dos meus pais, o desemprego e uma grande amargura foram me dominando e caí em profunda depressão!... E foi neste contexto de vida que me apresentaram o LETRAVIVA! O "astral" do grupo me "botou pra cima". Poucos sabiam da minha história [mas] não falavam nada e eu também me calava na tentativa de esquecer.

Fui me envolvendo por inteiro no projeto. Eu acreditava nele e queria que desse certo. Fizemos formação, articulamos, montamos grupos. [Uma das formadoras] me incentivou a assumir um grupo como educadora, assim vivi uma grande experiência. Minha vida foi se transformando... Eram senhoras idosas, senhores e até adolescentes. Aos poucos eles foram invadindo a minha vida e não tive como não me envolver na vida deles. Aconteceram muitas coisas nesses nove meses de LETRAVIVA: Emoção da primeira palavra lida, na construção da primeira frase... no emprego conseguido pelo C., fome, mortes, separações... Como não me envolver? Eles me colocavam como peça fundamental no dia-a-dia deles. No dia 29 de maio de 2004 uma grande festa na Praça Carlos Gomes selou esta linda conquista do nosso povo. Me emocionei com eles. Hoje, olho e me vejo inteira, recuperada. Já não preciso tomar antidepressivo. Mesmo com o desemprego, a filha distante, a ausência dos meus pais e a saudade deles, somada a todas as dificuldades que a vida oferece, eu vejo luz... luto por soluções. E o LETRAVIVA... "Viva letra, simples, popular e caseiro..." sem dúvida nenhuma foi fundamentalmente importante na minha retomada de vida. Por tudo isso eu quero deixar uma pequena mensagem; "Você que viveu passe adiante"!

(Educadora Raquel $\left.^{3}-04 / 06 / 2004\right)$.

3 Os nomes das educadoras são fictícios, preservando-se as suas identidades. 
Esse registro foi produzido espontaneamente pela educadora. É tão difícil escrever e ela escreveu sem ter sido cobrada. E mais, compartilhou com as outras pessoas do grupo. Por quê? O que a moveu a tomar a atitude autoral? Essas perguntas nos acompanhavam insistentemente naquele período; por isso, passamos a procurar os indícios de respostas nos movimentos vividos pelas educadoras em seus grupos de alfabetização, nas criações elaboradas por seus educandos e educandas, nas nossas ações recíprocas vivenciadas durante os Encontros de Formação e nos demais momentos de trabalho conjunto.

"Fui me envolvendo por inteiro no Projeto. Eu acreditava nele e queria que desse certo", afirmou Raquel. Tomando como referência questões enunciadas por Paulo Freire 4 para analisar essa escrita, podemos perceber que a formação que vivíamos cotidianamente no LETRAVIVA, encharcada dos riscos inerentes a uma obra aberta, promovia um sentido de pertencimento e de autoria do trabalho, potencializando a emergência das manifestações de recriação de conhecimentos e saberes construídos ao longo da vida. Procurávamos criar um ambiente propício à produção do conhecimento e não à pura e simples reprodução e transmissão de conteúdos, para que todos os sujeitos, educandos e educadores, experimentassem a re-existência a partir do diálogo e da criatividade do grupo.

As recriações de conhecimentos e saberes ${ }^{5}$, assim como uma outra e nova atitude perante a própria vida e a sociedade circundante, foram as constatações mais eloquentes encontradas no percurso investigativo, realizado no Programa de Pós-Graduação em Educação da PUC-Campinas, durante os anos de 20072009. Nos encontros de formação do LETRAVIVA ouvíamos constantemente do Professor Romualdo Dias" o convite "Vamos fazer da nossa vida uma obra

4 As questões insistentemente apresentadas por Paulo Freire quanto ao respeito, acolhida e diálogo com o saber do outro, sendo o outro qualquer pessoa que conosco compartilhe a vida ou a prática educativa, estão, no nosso entendimento, no cerne da ética que fundamenta a ação do educador comprometido com a transformação social. Cf. Pedagogia da Autonomia, 2003, p. 23 e Extensão ou comunicação? 1992, p. 43.

5 Segundo Freire, "fazer a história é estar presente nela e não simplesmente nela estar representado" (1993, p. 40), pois "é preciso reinventar o mundo. A educação é indispensável nessa reinvenção. Assumirmo-nos como sujeitos e objetos da História nos torna seres da decisão, da ruptura. Seres éticos" (FREIRE, 2006, p. 40).

6 Romualdo Dias, nosso querido parceiro na criação e sustentação teórica do Projeto LETRAVIVA, é professor da UNESP - Rio Claro e também atua na assessoria a movimentos populares há muitos anos. Foi assessor da Secretaria Municipal de Educação de Campinas nos anos de 2003 e 2004. 
de arte?" ${ }^{\prime}$ de tal sorte que o incorporamos ao nosso modo de existir. Esse convite-desafio foi sendo trabalhado por nós, educadoras e educadores com a singularidade inerente a cada pessoa, e podemos afirmar que repercute ainda nos ouvidos dos que tiveram oportunidade de vivenciar esta experiência transformadora de nossas práticas e, por extensão, de nossas vidas. Podemos afirmar que a pesquisa em nível de mestrado, tomando como tema a minha vivência e as das demais educadoras do Projeto LETRAVIVA, pode ser considerada um desdobramento do mesmo convite.

Os resultados de uma investigação científica nem sempre são quantificáveis, mas podem ser socializados porque, ao nos narrarmos como pesquisadores, educadores e educadoras que somos, repartimos um pouco de nossa vida e um modo de ser e estar no contexto de trabalho. Prado, Cunha e Soligo (2008, p.136) deram o nome de narrativas pedagógicas aos escritos que compartilham conhecimentos e saberes construídos durante a vida, na atuação profissional ou no percurso de pesquisa:

O que são narrativas pedagógicas? São memoriais, novelas de formação, cartas pedagógicas, crônicas do cotidiano, depoimentos, diários, relatos de experiência e de pesquisa, dentre outros registros em que os educadores documentam o que fazem, assim como suas inquietações, dificuldades, conquistas, sua produção intelectual. São textos que mobilizam o necessário diálogo entre os conhecimentos, saberes e experiências da formação e da profissão e que funcionam como plataforma de lançamento à reflexão sobre si mesmo e sobre sua ação profissional (PRADO; CUNHA; SOLIGO, 2008, p. 136).

7 Diversos autores trataram do tema de se tomar a vida como obra de arte, sendo o assunto bastante debatido no contexto da filosofia, das artes, das ciências humanas e das ciências sociais aplicadas. Uma das principais referências à vida como obra de arte pode ser encontrada em Leon Tolstoi, sendo seguido por Mahatma Gandhi. Também abordam o tema os filósofos Friedrich Nietzsche e Michel Foucault. Em torno das obras destes autores, podem ser encontrados muitos estudos, inclusive disponíveis na internet. Eventos científicos também são promovidos, como é o caso do recente "A vida como obra de arte: práticas e interferências", realizado na UFF entre os dias 13 e 14 de novembro de 2008. Disponível em: <http://ppgpsi-ufes.blogspot.com/2008/10/ vida-como-obra-de-arte-prticas-e.html $>$. Acesso em: 15/12/2008. Em nossa abordagem reafirmamos, com Paulo Freire, que a formação humana é um esforço indiscutivelmente ético e também estético. "Decência e boniteza de mãos dadas" (2003, p. 32). A práxis do educador, no seu contexto social, pode vir a ser uma experiência da educação como prática da liberdade. Da re-existência. Da transformação da vida em obra de arte. Um processo, portanto, de autoconstituição implicado nas dimensões realidade, mulher/homem, sociedade. 
Devemos registrar que Paulo Freire sempre foi referência obrigatória, tanto no trabalho desenvolvido no LETRAVIVA, como na nossa produção acadêmica: "Rever o antes visto quase sempre implica ver ângulos não percebidos. A leitura posterior do mundo pode constituir-se de forma mais crítica, menos ingênua, mais rigorosa" (FREIRE, 2006, p. 24). A partir dessa concepção de reflexão sobre a prática é que a pesquisa se nos impôs como necessidade para a retomada de questões que nos inquietavam e que demandavam o aprofundamento teórico. Ao compartilhar a pesquisa desejamos, além da reflexão, constituir laços de amizade e de reafirmação do pertencimento a um segmento profissional tão descuidado pela sociedade brasileira e pelos poderes constituídos: o dos profissionais da educação. Valorizar o trabalho destes sujeitos e promover a circulação dos seus saberes e conhecimentos é nossa intenção explícita, a fim de democratizar a produção acadêmica. Entendemos que a pesquisa pode se constituir como um momento singular de nossas vidas ao acolher a pluralidade das diversas vozes silenciadas, que na história de nosso país tão contraditório e fecundo em explorações, são relegadas ao esquecimento.

Vários cientistas têm reafirmado a necessidade da divulgação das pesquisas educacionais por admitirem que a ciência é uma construção social que não precisa e não deve ficar aprisionada nas universidades. Claro está que esse modo de compreender a ciência é também um posicionamento político. Como afirmou Paulo Freire (FREIRE, 1974, p.7), não há educação neutra e por extensão, do lugar social onde nos encontramos, sabemos que não há ciência neutra. A investigação científica no campo educacional cada vez mais tem refinado seus referenciais metodológicos para incorporar a experiência vivida, trazendo para o debate os complexos problemas enfrentados no cotidiano das salas de aula. Os autores aqui referidos explicitam com propriedade a intenção de nosso trabalho acadêmico, que produziu a sua reflexão a partir de narrativas singulares de algumas das educadoras do LETRAVIVA. Pudemos perceber que elas construíram novas possibilidades nas relações humanas vividas nos espaços educativos, criando continuamente o que Freire chamou de "inédito-viável" e que Freitas (2007, p. 19) assim comentou:

o inédito-viável não ocorre ao acaso nem se constrói individualmente. A criação do inédito-viável representa, sobretudo, uma alternativa que se situa no campo das possibilidades e não das certezas. Compreendido desse modo, o ato coletivo de sonhar encerra em si a possibilidade de superar as práticas tradicionalmente inquestionadas. Constitui-se em atitude crítica de formação que concebe a distância entre o sonhado e o realizado como um 
espaço a ser ocupado pelo ato criador. Assumir de modo coletivo esse espaço de criação abre possibilidades para que se consolidem propostas transformadoras e ineditamente-viáveis capazes de, progressiva e sucessivamente, tornarem os sonhos possíveis (FREITAS, 2007, p.19).

Muitos são os depoimentos feitos por educandos acerca da grande importância que representa em suas vidas a alfabetização e a possibilidade de transitar com desenvoltura no mundo letrado. Nossa pesquisa direcionou a sua atenção para a ressignificação da vida produzida pelas educadoras, a partir do trabalho educativo.

\title{
Educação como obra de arte
}

\author{
uma parte de mim é permanente \\ outra parte se sabe de repente \\ uma parte de mim é só vertigem \\ outra parte linguagem \\ traduzir uma parte noutra parte \\ que é uma questão de vida ou morte \\ será arte? \\ Ferreira Gullar
}

Ao agregarmos os saberes trazidos por todos os educadores e educadoras, o ambiente favorável germinou no Projeto LETRAVIVA. Desde o primeiro encontro criamos possibilidades de partilha de conhecimentos e de elaboração coletiva de propostas para serem desenvolvidas nos grupos. Na pequena narrativa escrita por uma das educadoras, é possível perceber como ela carregou para o seu trabalho no grupo as experiências e aprendizados que foi tecendo ao longo de sua vida:

O educador é aquele que com paciência, respeito, afeto, acredita que a aprendizagem é possível acontecer. A experiência que eu tenho como educadora começou com meus filhos e com a comu- 
nidade. Com os filhos, porque meu primeiro filho nasceu portador de Síndrome de Down. Desde que ele nasceu precisei aprender a lidar com ele. O médico, quando fez o cariótipo e constatou que ele era portador da Síndrome de Down, disse-me que se eu não cuidasse, ele ficaria como um bicho. Então, comecei a levar para a fisioterapia, fono, T.O., psicóloga etc. Enfim, aprendi a trabalhar a coordenação motora, com exercícios para pegar as coisas nas mãos, exercício para engatinhar. Visão, eu trabalhava com cores, tamanhos, grosso, fino, áspero, liso. Geometria: quadrado, círculo, triângulo etc. Depois comecei a participar na comunidade. Fui convidada para ser catequista. Fui catequista durante 4 anos, ensinando religião. Depois coordenei a comunidade durante 5 anos. Hoje eu atuo como Ministra da Palavra e da Eucaristia, além de colaborar na Tesouraria.

Fui convidada no ano passado para ser educadora do LETRAVIVA. Para mim, é muito gratificante saber que estou ajudando alguém a ler e escrever, como a S. F. que não sabia fazer nem a letra A. Hoje ela já escreve seu nome! E Dona A. que chorou na frente de seus colegas porque conseguiu ler tudo o que estava escrito na lousa! Também tem o C. que perdeu o serviço por não saber preencher o currículo. Hoje [ele] só não escreve, mas já aprendeu a ler algumas palavras. Dona M. O. assinava só com o dedo. Hoje ela já consegue assinar e escrever sozinha o seu nome. Enfim, todos os meus alunos estão evoluindo muito. Graças a Deus e ao LETRAVIVA por esta oportunidade de alfabetizar. Que Deus nos abençoe e nos dê força para continuarmos este trabalho. De fazermos do Brasil um país alfabetizado.

(Educadora Ester - novembro, 2004)

$\mathrm{Na}$ Educação Popular a investigação inicial do universo vivido pelos sujeitos e suas trajetórias existenciais potencializa a realização de um "raio x" do contexto social. A história de vida, tomada como "plataforma de lançamento" para a compreensão da sociedade dividida em classes, aproxima sem hierarquizar educadores e educandos. Todos compartilham a oportunidade de levantar o véu que encobre a razão do mundo capitalista ser organizado sob a égide da exploração do trabalho. É possível, então, a explicitação da condição social de exclusão nas vidas que carregam as marcas do pertencimento de classe. Um dos maiores danos para a autoimagem das pessoas é a introjeção e naturalização da inferioridade; por isso uma das questões fundamentais da Educação Popular é lançar luz sobre este processo a fim de colaborar com o resgate da humanidade roubada, conforme enfatizou Freire: "É importante ter sempre 
claro que faz parte do poder ideológico dominante a inculcação nos dominados da responsabilidade por sua situação" (FREIRE, 2000, p. 84). No regime de dominação em que os dominados precisam lutar para se apropriar da própria palavra, a reinvenção de si pode se realizar a partir da educação emancipatória. Na relação dialógica compreende-se que a educação ultrapassa a decodificação das palavras, abrindo janelas para novos horizontes. Sabemos que através das palavras nós, seres humanos, criamos os sentidos da existência. A "leitura do mundo", segundo Freire, desvela o sentido de as relações com elas serem relações de poder.

A narrativa a seguir foi produzida como um diário pessoal pela educadora Mariana. Selecionamos alguns fragmentos, pois o diário é longo:

Em 1983 fiz o magistério e assim que me formei fui dar aula em uma fazenda lá na Bahia, para uma classe multisseriada, aprendi muito com aquela classe, pois era um ensino voltado para quem trabalhava na lavoura. No ano seguinte trabalhei com uma classe de $1^{\mathrm{a}}$ série, isto na cidade, eram treze crianças mais [sic] sei que errei muito por não saber trabalhar com alfabetização de crianças. Como eu não tinha muito acompanhamento pedagógico eu fazia o que sabia. No ano seguinte, que era 1986 mudei para Campinas. Chegando aqui numa semana, na próxima já arrumei emprego em uma pré-escola, aquela sala era mantida pela Fundação Educar, e eu, como não tinha nenhum preparo para dar aulas em classe de alfabetização, devo muito a uma senhora que era a merendeira e a dona da sede onde funcionava a escola. Como era um local na periferia de Campinas, [vieram] várias professoras que não gostavam do local, da lonjura e acabavam desistindo. Como vim morar naquele bairro, fiquei lá durante um ano fazendo o que sabia e o que dona Carolina me ensinava. Apesar de ela não ser professora, ela era muito inteligente, e cada professora que vinha, ficava uma semana, ela adquiria conhecimentos, e nós duas juntas trabalhávamos com as crianças. Isso foi no ano de 1987. Em 1988 eu fui trabalhar em outra localidade com outras realidades, e com isto fiquei em classes de pré-escola até 1990. Quando foi em 1991, a prefeitura tirou-me a classe devido o meu magistério ser só de $1^{\mathrm{a}}$ a $4^{\mathrm{a}}$ série. Fui trabalhar na Secretaria de Educação com cargo administrativo, foi quando surgiu um concurso para alfabetização de jovens e adultos e eu passei. Fui chamada para substituir e fiquei vários anos como professora substituta de jovens e adultos. Em 1998 fiz uma inscrição como substituta para dar aula de $1^{\mathrm{a}}$ a $4^{\mathrm{a}}$ série, e trabalhei dois anos, 
e no ano de 2000 perdi todos os meus dois cargos por não ter passado em um concurso. Fiquei doente, desmotivada por tudo que aconteceu, e passaram vários anos, nem fui atrás de nenhum emprego. Trabalhei com vendas, mas não fui bem sucedida. No final de 2004, fiquei sabendo que havia um projeto de alfabetização na cidade, fui me informar e acabei abrindo uma classe e trabalhei 8 meses. Gostei muito desse trabalho que fiz durante esses oito meses, porque o projeto era uma coisa nova para mim, me tornei bastante emocionada ao voltar para a sala de aula depois de quatro anos, e com alfabetização de jovens e adultos. Neste Projeto que se chamava LETRAVIVA eu conhecia várias pessoas interessantes e pessoas humildes, interessante que ficou marcado: a D., a A., o professor Romualdo que deu um curso de Extensão Universitária para nós educadoras e professoras. Trabalhando no Projeto LETRAVIVA, foi como se eu tivesse mudado de país, em relação às outras atividades em sala de aula que eu já havia participado. Eu fiquei muito entusiasmada com a forma que cada uma de nós educadoras éramos tratadas. Nós éramos valorizadas como ser humano, de conversar olhos nos olhos, sentar pertinho uma das outras para trocarmos experiências, resolver nossos problemas de educadora, ou às vezes de educando. Foi uma coisa, ou melhor, uns momentos assim tão bons que à vezes eu tinha uma ideia para trabalhar um determinado assunto com meus educandos, eu estava deitada, ou às vezes fazendo o serviço de casa, eu parava, anotava tudo como seria feito e depois prosseguia o serviço ou até mesmo o meu descanso. Eu fiz tantos trabalhos no LETRAVIVA que às vezes penso porque não gravei para ficar registrado todos os momentos bons dos nossos encontros com educandos, com o pessoal de apoio que nos apoiava. Essas pessoas eram: Coordenadoras, estagiários, as educadoras, os educandos, os lojistas da cidade que nos doaram muitos materiais, coisas que eu nunca tinha conseguido quando dava aula formal. Uma colega ia atrás dos materiais, ela dizia que fazia marketing e depois ia só buscar as doações.

Quero fazer aqui um confronto ou um contraponto em relação à FUMEC $^{8}$ e LETRAVIVA. Na FUMEC eu aprendi muito na parte pedagógica, eram muitos cursos, palestras, muitos relatórios. Nós ficávamos muito presas em relatórios para entregar, muita burocracia em si. Mas foram muitos anos de experiências, vivências

8 FUMEC - Fundação Municipal para Educação Comunitária, subordinada à Secretaria Municipal de Educação de Campinas - responsável pelo primeiro ciclo da Educação de Jovens e Adultos do Ensino Fundamental. 
etc. e muito mais. O LETRAVIVA como é uma educação popular, nós fazíamos de tudo em classe, quer dizer: coisas prazerosas, os educandos eram o nosso centro de interesse. A gente inventava coisas na hora, as discussões, os bate-papos do momento eram um ponto de partida. No LETRAVIVA nós éramos iguais; a relação educadora e educando surgia numa fluência perfeita que trabalhávamos vários temas tudo entrelaçado a partir de uma conversa do dia-a-dia.

(Educadora Mariana, fevereiro - 2005)

O diário instiga e comove ao revelar a constituição de Mariana como educadora. Infelizmente tivemos que selecionar apenas alguns trechos, especialmente os relativos ao trabalho desenvolvido no LETRAVIVA, para atender aos requisitos da produção desse artigo. Ainda assim, podemos vislumbrar suas dificuldades, seu trajeto marcado pela precariedade das condições de trabalho e por suas sucessivas tentativas de superação. Sua crítica à burocracia e ao ensino "bancário" é tão honesta, brotando da experiência vivida. Tão simples e potente ao mesmo tempo!

Apresentamos a seguir mais um dos registros de educadoras recolhidos durante a pesquisa. Diferentemente dos anteriores, elaborados espontaneamente e/ou para fins diversos dentro do projeto LETRAVIVA, esse foi escrito especialmente para colaborar com a nossa investigação. Foi produzido em 2008, portanto, com um olhar retrospectivo e reflexivo sobre o trabalho desenvolvido nos anos de 2003 e 2004 :

Toda pessoa tem sua História de vida, História que se vai construindo, tecendo, entrelaçando, sem nunca perder o fio condutor. No ano de 2003, no Palácio dos Azulejos, nesta cidade, participei da primeira reunião, onde depois de vários anúncios, foi exposto o que seria o programa de alfabetização Brasil Alfabetizado, do governo federal e que em Campinas recebeu o nome de LETRAVIVA.

Me comprometi em ser educadora do Projeto LETRAVIVA, e confesso que até hoje, mesmo não fazendo parte de nenhum grupo de alfabetização, me removem as entranhas cada vez que me recordo daquele grupo que tanto me ensinou e despertou para o meu ser mulher, e assim para outros tipos de alfabetização. Me surpreendia a cada tarde de encontro. Elas, digo elas porque no grupo só havia mulheres, não por falta de convites 
aos homens também, mas no grupo só tinha elas, desde uma bem pequena que ali aprendeu a dar seus primeiros passos, pois só tinha 10 meses de idade, até uma que na época tinha 75 anos e que ali, naquele grupo, aprendeu a assinar o seu nome e foi um momento que todas choramos, simplesmente por ver sua alegria e empenho.

Penso que a primeira postura da pessoa que se dispõe a "alfabetizar" é tirar as sandálias dos pés, porque a vida de cada pessoa é muito sagrada e está sempre em movimento. Muitas palavras foram escritas em forma de poesia, retratando a própria vida. Em uma casa onde não havia janelas, não entrava nenhum raio da luz do sol, simplesmente por não interessar se era noite ou dia, a palavra foi escrita de forma diferente, através de diversas telhas de vidro espalhadas no telhado. Algumas palavras foram escritas e lidas bem baixinho, ao pé do meu ouvido. Foi um grito sussurrado, um gemido de denúncia: "Eu durmo sempre bem abraçada com meu companheiro, mesmo quando ele está bêbado, pois tenho em casa uma "menina-moça", e não vou me perdoar se ele fizer algum mal pra ela". Sim, muitas palavras foram escritas e lidas através de danças, desenhos, sorrisos, festas, passeios e também, na surpresa da descoberta de nossos corpos de mulher com todo o seu encanto, mistério, mas que também é alvo de diversas formas de discriminação e preconceito, maus tratos, piadas de mau gosto e de muitas formas de tabus. A experiência no Projeto LETRAVIVA me fez despertar para a alegria de acolher e de me deixar ser acolhida pelas pessoas, me ajudou a ver que o mundo vai muito além de mim e das minhas próprias necessidades. Me deu possibilidades de compreender que a vida vai se tecendo em sonhos e que somente em comunhão poderemos partilhar de um mundo mais justo, mais de acordo com a vontade de Deus. E que a alfabetização vai mais além de "ensinar a ler e escrever", que é uma arte colocar som nas letras, cores nas palavras e que para isso é preciso usar as técnicas que temos por natureza, aguçando todos os nossos sentidos, olfato, tato, visão, paladar e audição. Me ensinou a ser mais mulher e cúmplice de tantas mulheres, que também fizeram a opção de tirar as sandálias, porque a vida é sagrada e merece ser vivida com dignidade e em uma festa onde caiba todas as pessoas, este é o sonho de Deus, e nós somos co-responsáveis para que ele se torne realidade.

(Educadora Marta, 30/03/ 2008) 
Podemos perceber nos registros das educadoras:

A ideia do inacabamento dos seres humanos e da história como campo aberto de possibilidades a serem recriadas pelos sujeitos. "Condicionado pelas estruturas econômicas, não sou, porém, por elas determinado [...] É percebendo e vivendo a história como possibilidade que experimento plenamente a capacidade de comparar, de ajuizar, de escolher, de decidir, de romper" (FREIRE, 2000, p. 57)

A concepção de mundo marcada pela ideia de movimento, processo em constante construção: "Não há cultura nem história imóveis. O mundo não é. O mundo está sendo" (FREIRE, 2000, p. 30 e 79).

A concepção de homem e de mulher como sujeitos e seres de relações. "Não sou apenas objeto da História mas seu sujeito igualmente. No mundo da História, da cultura, da política, constato não para me adaptar mas para mudar" (FREIRE, 2000, p. 79).

Na vida de algumas educadoras a repercussão do trabalho foi emblemática. Segundo depoimentos colhidos durante os anos de 2003 e 2004, e também durante a realização da pesquisa, pudemos constatar que esta vivência se tornou

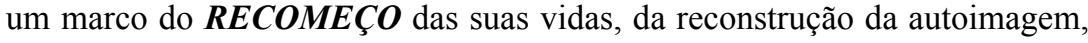
da inserção social:

Ao escolher ir aos que ficaram à margem, ao convocá-los ao círculo do diálogo e não à monotonia das carteiras em filas silenciosas, o educador desta escolha aprende a viver a sua realidade. Ao dizer aos seus estudantes que digam o que pensam para que daí algo se construa da maneira mais solidária possível, o educador popular aprende a lidar, com o mistério do outro (BRANDÃO, 2002, p. 43).

Por meio das histórias narradas vislumbramos e compreendemos melhor o humano e a humanidade que há em nós, assim como a explicitação de saberes e de conhecimentos que compõem nosso repertório cultural. Através do relato da pesquisa notamos também que agregar o saber do outro amplifica as vozes outrora esquecidas ou suprimidas do discurso acadêmico. Na nossa compreensão esta é uma das possibilidades de não desperdiçarmos a experiência, conforme sugeriu Boaventura de Sousa Santos e de inventarmos o inédito-viável do qual nos falou Paulo Freire. 


\section{Concluindo... Vivendo a pesquisa como possibilidade de "esticar horizontes"}

A partilha dos fragmentos de histórias vividas foi feita encorajada pelas transformações provocadas em nós e também para dar a ver como experiências singulares, não burocratizadas, podem se transformar em opções para a criação de currículos vivos. O aprendizado durante o percurso da pesquisa tem se convertido em momento singular, de re-encontro com a nossa própria subjetividade, de questionamento de nossos valores e crenças e de intensificação do diálogo, agora alargado para além do grupo de educadoras populares:

O pesquisador que trabalha com narrativas interroga-se sobre suas trajetórias e seu percurso de desenvolvimento pessoal e profissional, mediante a escuta e a leitura da narrativa do outro. A perspectiva colaborativa da pesquisa com narrativas de formação implica aprendizagens e teorizações sobre as práticas tanto do pesquisador quanto dos pesquisados (SOUZA, 2007, p. 19).

$\mathrm{Na}$ narrativa elaborada até aqui tentamos trazer à luz alguns dos movimentos vividos. Concordamos com Larrosa quando afirma que a experiência "conduz até onde não estava previsto, à consciência de que o eu não é senão uma contínua criação, um perpétuo devenir: uma permanente metamorfose" (LARROSA, 2003, p.39). Nos contatos com as educadoras percebemos que elas demonstram muita alegria e disponibilidade para compartilhar suas experiências, expondo inclusive momentos dramáticos de suas vidas, ao mesmo tempo, encharcando de significados os seus atos educativos. Connelly e Clandinin, defendendo a pesquisa narrativa, afirmam:

La investigación narrativa se utiliza cada vez más en estudios sobre la experiencia educativa. Tiene una larga historia intelectual tanto dentro como fuera de la educación. La razón principal para el uso de la narrativa en la investigación educativa es que los seres humanos somos organismos contadores de historias, organismos que, individual y socialmente, vivimos vidas relatadas. El estudio de la narrativa, por lo tanto, es el estudio de la forma en que los seres humanos experimentamos el mundo. De esta idea general se deriva la tesis de que la educación es la construc- 
ción y la reconstrucción de historias personales y sociales; tanto los profesores como los alumnos son contadores de historias y también personajes en las historias de los demás y en las suyas propias (CONELLY; CLANDININ, 1995, p.11-12).

O trabalho com as histórias de vida dos educandos, educandas e dos educadores, possibilitou que o repertório individual destes sujeitos cognoscentes fosse acrescido por meio de novas aproximações do real e do vivido. As experiências de formação e de (auto)formação confirmam que há uma práxis transformadora no trabalho que acolhe a todos como sujeitos produtores do conhecimento. "Vamos fazer da nossa vida uma obra de arte?" convidava nosso amigo e professor Romualdo. Optamos por seguir vivendo, cada qual com seu jeito e possibilidade, a vida como uma obra de arte inconclusa, pois como cantou Gonzaguinha (1982), maravilhosamente:

Toda pessoa sempre é as marcas

Das lições diárias de outras tantas pessoas

É tão bonito quando a gente entende

Que a gente é tanta gente

Onde quer que a gente vá

É tão bonito quando a gente sente que

Nunca está sozinho por mais que pense estar.

\section{REFERÊNCIAS}

BRANDÃO, C. R. A educação popular na escola cidadã. Petrópolis: Vozes, 2002.

CONNELLY, F. M.; CLANDININ, D. J. Relatos de experiencia e investigación narrativa. In: LARROSA, J. (Org.). Déjame que te cuente: ensayos sobre narrativa y educación. Barcelona: Editorial Laertes, 1995, p. 11-59.

FREIRE, P. Uma educação para a liberdade. 4. ed. Porto: Dinalivro, 1974. . Extensão ou comunicação? 10. ed. Rio de Janeiro: Paz e Terra, 1992. . A importância do ato de ler. 28. ed. São Paulo: Cortez, 1993. 
. Pedagogia da indignação. São Paulo: UNESP, 2000. . Pedagogia da autonomia. São Paulo: Paz e Terra, 2003. . À sombra desta mangueira. 8. ed. São Paulo: Olho d'Água. 2006.

FREITAS, A.L.S. A urgência de uma práxis transformadora e viável na educação do século XXI. Revista de Educação da AEC. Rio de Janeiro, n. 143, p. 07-20, abr./ jun. 2007.

GONZAGUINHA. Caminhos do coração. In: GONZAGUINHA. Caminhos do coração. [S.1.] EMI-Odeon, 1982. 1 CD. Faixa 10.

GULLAR, F. Toda poesia (1950-1980). 4. ed. Rio de Janeiro: José Olympio, 1987. LARROSA, J. Pedagogia profana. Belo Horizonte: Autêntica, 2003.

MÉSZÁROS, I. A educação para além do capital. São Paulo: Boitempo, 2005.

PRADO, G. V. T.; CUNHA, R. C. O. B.; SOLIGO, R. Memorial de formação: uma narrativa pedagógica de profissionais da educação. In: PASSEGGI, M. C.; BARBOSA, T. M. N. (Org.). Memórias, memoriais: pesquisa e formação docente. Natal, RN: EDUFRN; São Paulo: Paulus, 2008, p. 135-152.

SANTOS, B. S. O Fórum Social Mundial: Manual de Uso. São Paulo: Cortez, 2005.

SANTOS, B. S. Para uma sociologia das ausências e uma sociologia das emergências. In: SANTOS, B.S. (Org.). Conhecimento prudente para uma vida decente. São Paulo: Cortez, 2004.

SOUZA, E. C. História de vida e práticas de formação. Histórias de vida e formação de professores, SEED-MEC, Boletim 01, mar. 2007.

VELOSO, C. Cajuína. In: Cinema Transcendental. Rio de Janeiro: PolyGram, 1979. 1 disco sonoro. Lado 2, faixa 3.

VIOLA, P. Rumo dos ventos. In: A toda hora rola uma história. Rio de Janeiro: Transamérica, 1982. 1 CD. Faixa 1.

Texto recebido em 05 de março de 2009.

Texto aprovado em 28 de maio de 2009. 